\title{
Smart Housing for Reducing Energy Use in Single- Households, Emphasizing Effective Energy Management
}

\author{
S.J. Park ${ }^{a}$, M.J. Kim ${ }^{\text {b, }}$ and S.Y. Kim ${ }^{c}$ \\ ${ }^{a}$ Department of Interior and Environmental Design, Keimyung University, Republic of Korea \\ ${ }^{b}$ Department of Housing and Interior Design, Kyung Hee University, Republic of Korea \\ ${ }^{c}$ Department of Energy Engineering, Keimyung University, Republic of Korea \\ E-mail: sjpark@kmu.ac.kr, mijeongkim@khu.ac.kr, energy@kmu.ac.kr
}

\begin{abstract}
Single-households, one of the new housing types to emerge recently, seem to experience difficulties in the management of energy use due to the short duration of their residence. However, there has been little study on effective energy management in singlehouseholds. If we can find solutions that reduce energy consumption through effective management, the total energy consumption across this housing type could be decreased, even though the reduction in energy use per single-household may be small. The main purpose of the research is to provide appropriate solutions for the effective management of energy use for single-households by applying smart technologies. For the implementation of smart housing, primarily we identified single-households' patterns of electricity use through our investigation. We categorized six representative types of singlehouseholds based on the results of a questionnaire survey, and extracted the patterns of electricity use in each type of single-household through interviews. Based on the results, smart housing solutions for single-households would be provided by emphasizing the effective management of electricity use. By maximizing smart spaces in single-households, sustainable and healthy housing would be realized in terms of energy saving. Further, this research would be a basis for enhancing the quality of housing environments for single-households.
\end{abstract}

Keywords -

Smart Technology; Single Households; Energy Consumption, Energy Management

\section{Introduction}

One third of the energy consumed in Korea is attributable to the built environment, and households in residential buildings contribute significantly to the magnitude of energy consumption in Korea. Significantly, the number of single-households has recently increased (now $23.8 \%$ of the total number of households) and these single-households appear to experience difficulties in the management of energy use due to the short duration of their residence. However, little study has taken place on effective energy management strategies for single-households. Our research starts by questioning how the energy use of single-households could be managed effectively through smart technologies. In general, the energy consumption in households includes electricity and gas for heating, cooking and hot water. However, this research focuses on the electricity consumed by single-households because the amount of the electricity consumed in single-households has become two and half times that of four-person households [1]. In particular, by analyzing lifestyle patterns in residential buildings, it was found that the single-households use more electronic appliances than the four-person households. Our research was mainly motivated by these findings on the single-households. We believe that the total amount of energy consumption could be decreased, although the reduction in energy use in each individual singlehousehold may be small.

The main purpose of the research is to provide appropriate solutions to the effective management of energy use for single-households by applying smart technologies. Our assumption is that smart housing might have the potential to reduce energy consumption by allowing the efficient use of energy in singlehouseholds. To facilitate the implementation of smart housing, primarily the patterns of electricity consumption in single-households should be identified and analyzed in order to address the features and problems to be considered for the effective management of energy use. Thus, we investigated single-households' patterns of electricity use with a focus on home appliances and lighting. Through the investigation, we could provide customized solutions to the different types of single-households in terms of electricity use. By emphasizing behaviors in daily life, this research would provide single-households with practical solutions that allow them to consume electricity more 
efficiently, eventually leading to a reduction in their expenditure for energy.

\section{Related Works}

\subsection{Single-Households and Energy Use}

The single-household is a new housing type that should be considered as important in housing studies because its effect on the housing industry, peoples' lives, and further, all of society might be immense. It has been reported that single-households are more interested in taking advantage of any conveniences available to support their lifestyle, and so employ more electric devices for their daily life. Above all, they try to save time and effort using smart appliances when they have to do housework [2, 3]. Thus, many researchers have paid much attention to the patterns of energy use by single-households. For example, researchers in the Energy department in the state of North RhineWestphalia in Germany investigated the patterns of electricity use, targeting 0.4 million people through the website "Stromcheck fur Haushalte". They found that the patterns of electricity in single-households differ from those in other types of households in terms of twelve home appliances. However, the occupant has the predominant effect on the energy use in singlehouseholds. As much as $80 \%$ of the measured variation may depend on the inhabitants' behavior $[4,5]$. There are studies that showed that energy consumption is mainly influenced by the lifestyle of their occupants, such as schedule profiles of lights and electrical devices [6]. Thus, they tried to identify residents' energylifestyles because the actual conditions of energy use first need to be understood. They collected data on their energy-saving behaviors or use of electrical appliances according to individual schedules $[7,8]$. Further, some researchers found lifestyle factors reflecting social and behavioral patterns associated with air conditioning, laundry, personal computer and TV usage[9].

\subsection{Energy Savings and Strategies}

There have been, in general, three approaches to the reduction of energy consumption in residential buildings[10]: implementing effective building performance to minimize heating and cooling loads, developing efficient home appliances to consume low amounts of energy, and promoting 'energy-conscious' behaviors among residents. For example, many researchers have tried to design or develop buildings that operate effectively in terms of energy savings by adopting eco-friendly features such as green rooftops, LED lamps and renewable energy sources [11]. Recently, energy saving information technology (IT) such as monitoring systems and standby power have been considered important. For example, smart metering systems using in-home display (IHD) allow residents to be aware of how much energy they use, naturally leading to a reduction and changes in the pattern of energy use by residents [12]. Particular attention was given to individual appliances to optimize the design and assess the use of energy consumption indictors [10]. Some researches dealt with intelligent remote control systems or a system to manage thermal and illuminance comfort to save energy[13, 14]. For maximizing the energy efficiency of power networks, researchers tried to identify an optimized scheduling algorithm for each device load, considering the characteristics of various home appliances [15].

Rather than energy technology and smart devices, some researchers have tried to identify ways to influence residents' energy-saving attitudes and the effects of the adopted methods on their energy-saving behaviors [16, 17]. This approach is a user-centric approach emphasizing residents' perception of energy saving. The energy-related behavior of the residents depends on many factors such as energy prices, energy policy including deregulation of energy markets and support for renewable energies, environmental concerns such as pollution and global warming, and technical development such as control systems and improved heat pumps [18]. To encourage citizens' involvement in energy savings, Busan city, Korea administration adopted an energy incentive system that motivates residents to reduce domestic electricity use by providing financial rewards. Through the adoption of the incentive system, $66 \%$ of participants managed to save energy compared to the same period in the previous year [19].

\section{Research Method}

We conducted a questionnaire survey to investigate the energy use of single-households in our previous research. Based on the results, we categorized six types of single-households with a focus on their lifestyles. Six subjects representing each type of single-household were recruited and interviewed in depth in terms of their electricity use behaviors associated with home appliances and lighting. The general features of the subjects are as shown in Table 1.

Table 1.Six Representative Subjects

\begin{tabular}{ccccc}
\hline $\begin{array}{c}\text { Subject } \\
\text { (age) }\end{array}$ & Gender & $\begin{array}{c}\text { Housing } \\
\text { size }\end{array}$ & Job & $\begin{array}{c}\text { time spent } \\
\text { at home }\end{array}$ \\
\hline A (65) & F & $79.2 \mathrm{~m}^{2}$ & Nil & 16 hours \\
B (66) & M & $66 \mathrm{~m}^{2}$ & Nil & 15 hours \\
C (36) & F & $62.7 \mathrm{~m}^{2}$ & Worker & 12 hours \\
D (34) & M & $42.9 \mathrm{~m}^{2}$ & Worker & 13 hours \\
E (21) & F & $33 \mathrm{~m}^{2}$ & student & 10 hours \\
F (20) & M & $49.5 \mathrm{~m}^{2}$ & student & 7 hours \\
\hline
\end{tabular}


By investigating subjects with different ages, genders and jobs, we tried to identify the patterns of electricity use that reflected their lifestyles, to find a way to save energy. All subjects lived in multiplex housing, but the housing sizes and the time spent at home differed.

We investigated at what time and for how long they generally use home appliances and lighting on weekdays. We did not include the electricity use at weekends because it could be quite different from that of weekdays. In addition, we considered twenty-three appliances that are used often, but consume a great deal of electricity. We excluded air conditioners and electric fans from the appliance list because they are related to seasonal factors. Rather than the patterns of electricity use that vary seasonally, we tried to find the patterns of electricity use that may vary according to the number of appliances and the amount of time operated. The electricity consumption per hour was calculated by referring to data sources derived from ENERGY STAR, a joint program of the U.S. Environmental Protection Agency and the U.S. Department of Energy. The standard electricity consumption for the appliances is as shown in Table 2.

Table 2.Standard Electricity Consumption for the

\begin{tabular}{|c|c|c|}
\hline \multicolumn{3}{|c|}{ Appliances } \\
\hline Appliances & Watt/Hour & Watt/Min.(Sec.) \\
\hline Hair Dryer & 1538.00 & 25.63 \\
\hline Coffee Machine & 1500.00 & 25.00 \\
\hline Microwave & 1500.00 & 25.00 \\
\hline Iron & 1100.00 & 18.33 \\
\hline Toaster & 1100.00 & 18.33 \\
\hline Vacuum Cleaner & 650.00 & 10.83 \\
\hline Clothes Washer & 425.00 & 7.08 \\
\hline Espresso Machine & 360.00 & 6.00 \\
\hline Blender & 300.00 & 5.00 \\
\hline LCD TV & 213.00 & 3.55 \\
\hline Video Game Player & 195.00 & 3.25 \\
\hline & 100.00 & 1.67 \\
\hline Refrigerator * & 83 & $1.38(0.023)$ \\
\hline Monitor & 150.00 & 2.50 \\
\hline Computer & 120.00 & 2.00 \\
\hline Curling Iron & 90.00 & 1.50 \\
\hline $\begin{array}{c}\text { bedroom/living room } \\
\text { lighting }\end{array}$ & 20.00 & 0.33 \\
\hline bedroom stand lighting & 60.00 & 1.00 \\
\hline bathroom lighting & 10.00 & 0.17 \\
\hline $\begin{array}{l}\text { kitchen/dining room } \\
\text { lighting }\end{array}$ & 10.00 & 0.17 \\
\hline desk lamp/floor lamp & 25.00 & 0.42 \\
\hline Stereo & 60.00 & 1.00 \\
\hline Laptop & 50.00 & 0.83 \\
\hline Printer & 45.00 & 0.75 \\
\hline Aquarium & 30.00 & 0.50 \\
\hline Clock Radio & 10.00 & 0.17 \\
\hline Rice Cooker & $\begin{array}{c}1000.00 \\
95.00\end{array}$ & $\begin{array}{c}16.67 \\
1.58\end{array}$ \\
\hline
\end{tabular}

The electricity consumption for each appliance was calculated by multiplying the time used by the average electricity consumption. For example, the electricity consumption for a refrigerator was calculated according to the number of opening behaviors of the door because opening behavior consumes a lot of electricity. The time spent opening the door was regarded as ten seconds. Especially, the lighting equipment was divided into fixed lights in rooms and movable lights such as floor lamps and desk lamps. The reason for differentiating the lighting is that many residents tend to leave fixed lights on while they stay at home. It was expected that by controlling such behaviors through smart management, the electricity use could be decreased. The electricity consumption for lighting was calculated taking into consideration the time spent at home.

In this study, we suggested a solution for managing electricity use from the aspect of the elasticity of demand in electricity prices. The TOU (Time of Use) and flat electricity rate are as illustrated in Figure 1.

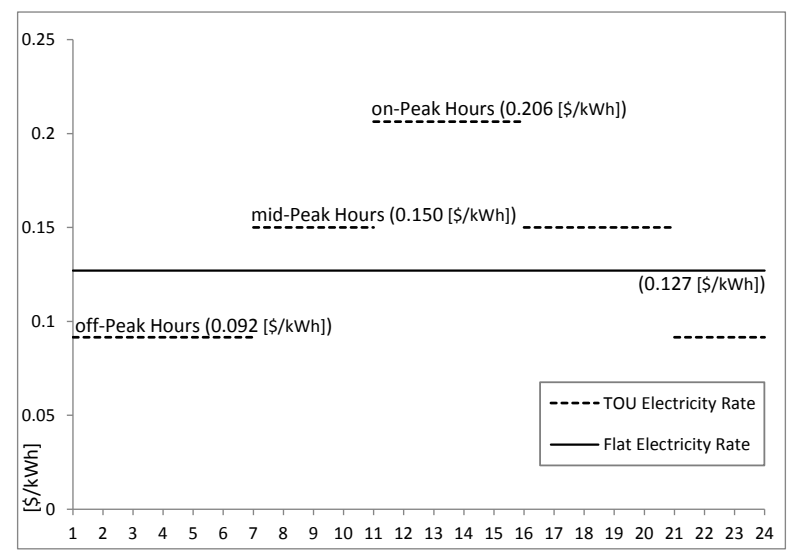

Figure 1. TOU and Flat Electricity Rate

Generally, the demand decreases as a product rises in price; the demand curve defines the elasticity around a demand price. The elasticity can be expressed as:

$$
\varepsilon=\frac{\Delta d / d_{0}}{\Delta p / p_{0}}
$$

$\Delta d, \Delta p$ indicate the variation in demand and price, and $d_{0}, p_{0}$ indicate the price demand at the reference point. Therefore, the change in the electricity consumption caused by the change in the electricity price, at time $t$, can be expressed as:

$$
\Delta d_{t}=\varepsilon_{t} \cdot \Delta p_{t}
$$




\section{Result}

\subsection{The Patterns of Electricity Use by Six Representative Subjects}

Pattern graphs of the energy use per subject are as shown in Figure 2 to Figure 3.

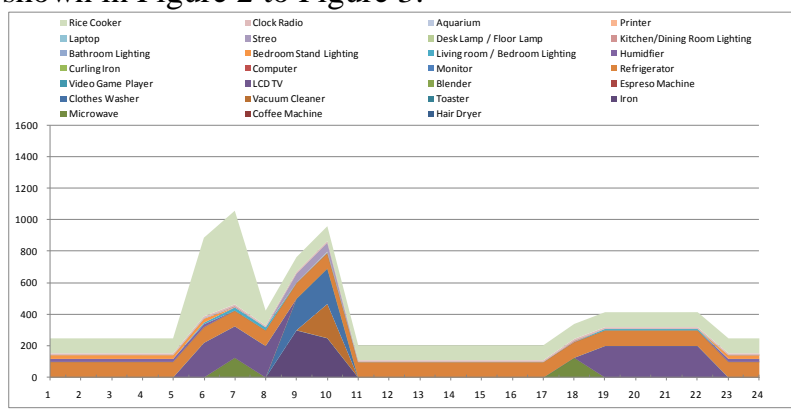

Figure 2. Male (66) Electricity Consumption Pattern

The 66-year-old male mainly uses electricity in the morning and evening, using 9278.28wh on average. This electricity use is the second highest; only the 66year-oldfemale subject uses more. The main times that electricity is consumed are between 5:00 and 11:00 and between 17:00 and 22:00. In particular, between 6:00and 7:00, electronic appliances such as a microwave, a LCD TV and a rice cooker are used simultaneously and intensively. Also, between 9:00and 10:00, electronic appliances such as a clothes washer, iron, and vacuum cleaner are used at the same time when doing household chores. To prepare dinner, he starts to use electricity in the late afternoon. Although he does not use many electronic appliances, the total electricity consumption is not small because the rice cooker is set to warm for 24 hours, similarly to the refrigerator. He does not have many lighting devices and does not turn them on for long periods of time. In particular, the lighting in the kitchen and dining room is rarely used. The stand lighting in a bedroom is an incandescent lamp, which consumes 25wh per hour, so the electricity consumption for lighting is not low.

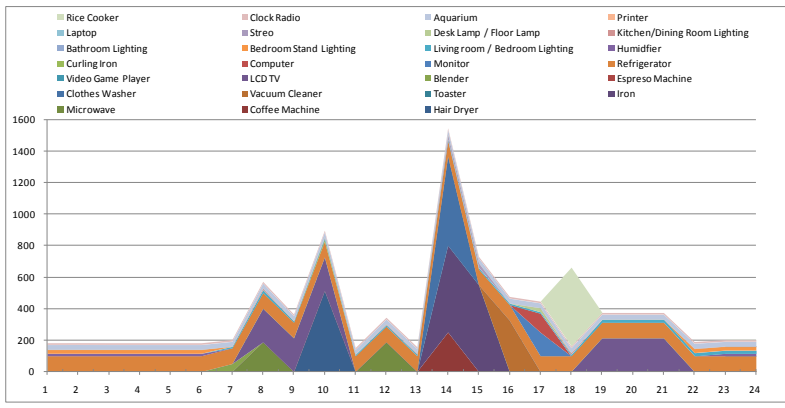

Figure 3. Female (65) Electricity Consumption Pattern

The 65-year-old female uses 9328.5wh on average, which is higher than all other subjects. The main times that electricity is consumed are between 7:00 and 11:00 and between 17:00 and 22:00. In the morning, she uses a LCD TV, in addition to a microwave used to prepare breakfast. In the afternoon, she uses a microwave and a coffee machine for lunch, and an iron and a clothes washer for chores. Compared to the other subjects, she uses high amounts of electricity for clocks, radios and an aquarium that is on 24 hours. In particular, electronic appliances such as a microwave, a LCD TV and a rice cooker are used simultaneously between 6:00 and 7:00. In addition, electronic appliances such as a clothes washer, an iron, and a vacuum cleaner are used when doing household chores between 9:00 and 10:00. On average, she uses quite a lot more electricity for lighting than the other subjects. The lighting in bedrooms or a living room is used in the afternoons due to her longsightedness. She also has a habit of turning on stand lighting, consuming large amounts of electricity continuously at night.

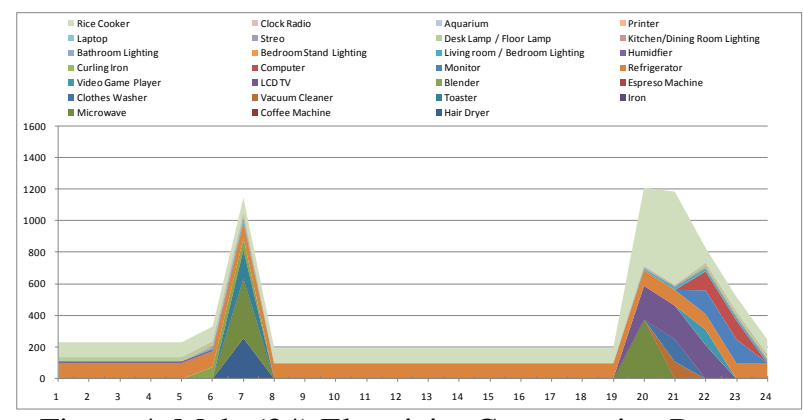

Figure 4. Male (34) Electricity Consumption Pattern

The 34-year-old male mainly consumes electricity in the morning and late evening, using 8987.04wh on average. The main times that electricity is consumed are between 6:00 and 8:00 and between 19:00 and 23:00. Compared to the two oldest subjects, he consumes electricity intensively in the early morning and late evening because he is at work during the day. Before going to work at 7:00, he uses a toaster, a blender and a hair-dryer. After returning home, he uses electricity intensively for dinner and household chores. Between 20:00 and 22:00, he uses a clothes washer and a vacuum cleaner with other appliances such as a rice cooker and a microwave. In particular, he plays video games and enjoys leisure activities such as watching TV and web surfing. Therefore, the electricity consumption is highest in the late evening. He also uses the rice cooker's warm option continuously (24 hours). He does not use many lighting devices, but he often leaves the desk lamp on while he sleeps at night, so the amount of electricity used for lighting is rather high. 


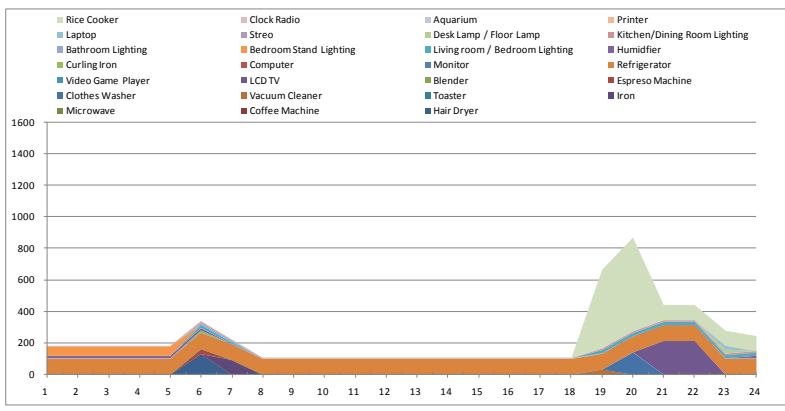

Figure 5. Female (36) Electricity Consumption Pattern

The 36-year-old female mainly uses electricity in the early morning and evening, using 5452.89wh on average. The main times that electricity is consumed are between 5:00 and 8:00 and between 18:00 and 23:00. Before going to work at 6:00, she uses an espresso machine and a blender for breakfast, in addition to a hair dryer. Compared to the other subjects, she does not use many electrical appliances to cook breakfast. Rather, she consumes comparatively high amounts of electricity using a hair dryer and an iron to care for her appearance. After returning home from work, she uses electricity intensively to prepare dinner and do household chores. In particular, between 19:00 and 22:00, she uses several appliances such as a rice cooker, a clothes washer and a vacuum cleaner simultaneously. Differing from the male subjects, she cancels the rice cooker's warm option before going to bed, which implies that she intends to reduce electricity consumption. Regarding lighting devices, she leaves lighting on in bedrooms, the living room, the kitchen and the dining room continuously in the evening, and uses an incandescent light for the standard lamps in bedrooms. The amount of electricity consumption for lighting is comparatively high.

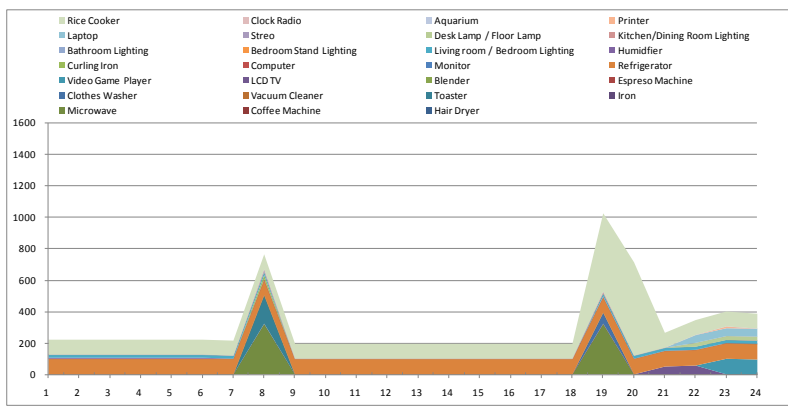

Figure 6. Male (20) Electricity Consumption Pattern

The 20-year-old male undergraduate student uses 7401.19wh electricity on average in the morning and evening. He mainly consumes electricity between 7:00 and 9:00 and between 18:00 and 20:00. Before going to university at 7:00, he uses a microwave and a toaster to prepare breakfast. Unlike the female of similar age, he does not use a hair dryer or an iron. Although he is at home for the shortest amount of time compared to the other subjects, he consumes a great deal of electricity because he leaves a rice cooker and lighting on for 24 hours continuously. He seems to be unaware of the possibility of energy saving. He mainly uses electricity from 18:00 to 20:00 because he does various activities intensively such as dinner preparation and household chores at that time. In spite of using less lighting devices, the amount of electricity consumption is comparatively high because the lighting is on continuously in bedrooms and the living room from the evening through to the next morning.

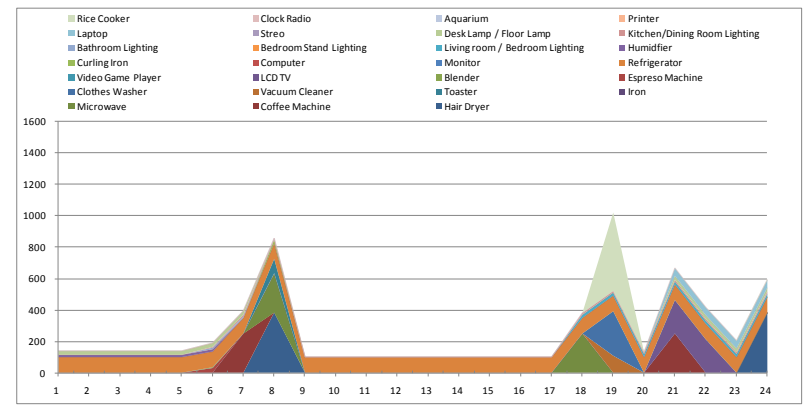

Figure 7. Female (21) Electricity Consumption Pattern

The 21-year-old female undergraduate student uses 6461.29 wh electricity on average mainly in the morning and evening. The main times that electricity is consumed are between 7:00 and 9:00 and between 18:00 and 24:00. Before going to university at 8:00, she uses a coffee machine, a microwave and a toaster to prepare breakfast, in addition to a hair dryer. Compared to other subjects, the time spent using a hair dryer is longer because she does her hair twice a day, morning and evening. After school, she does activities intensively such as dinner preparation and household chores. Therefore, the electricity consumption is high in a day. In particular, from 18:00 to 19:00, she uses appliances such as a clothes washer and a vacuum cleaner, but cancels the rice cooker's warming option after she uses it for dinner. Thus, compared to subjects who leave the rice cooker on the warm option continuously, the amount of electricity used by the rice cooker is comparatively low. Regarding lighting devices, she leaves the lighting on continuously in the bedroom and living room before going to bed. She also turns the incandescent desk lamp on and leaves it on until the next morning, so electricity consumption is high.

\subsection{Comparison of Patterns of Electricity Use by Six Subjects}

Figure 8 illustrates the patterns of energy use of the six subjects. Largely, the electricity use of the six subjects are distributed in the morning and evening except the 65-year-old female. Five subjects use electronic appliances intensively during the time spent 
at home.

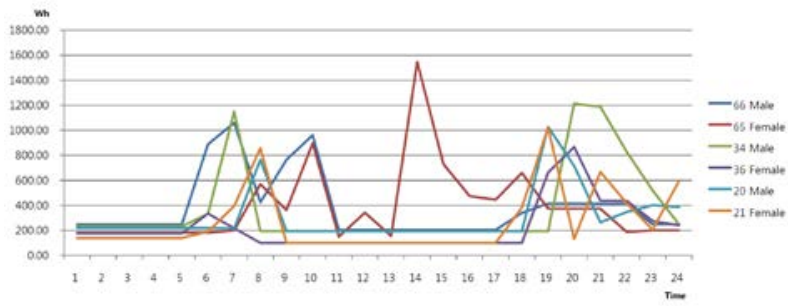

Figure 8. Comparison of Patterns of Electricity Use

There are a few differences in the time periods when the electrical appliances are used among the six subjects. Firstly, the 65-year-oldmale and the 66-year-oldfemale, who spend longer at home than the other four subjects, use electronic appliances moderately, while the other four use electronic appliances intensively and simultaneously. Secondly, the 34-year-old male and the 36-year-oldfemale consume electricity intensively in the morning and evening. They use various electronic appliances for breakfast and dinner preparation, household chores and leisure activities simultaneously. Thirdly, the 20-year-old male person and the 21-yearold female persons show similar patterns of electricity use, consuming in the late morning and early evening compared to other subjects because they have more flexible time schedules.

The patterns of energy use are different according to gender. Firstly, electricity consumption is high for the females because the females use more electronic appliances than the males. Also, the females use electronic appliances such as hair dryers, irons and bedroom standard lamps for longer periods of time. However, there are a few other differences between males and females because females attempt to reduce energy consumption by turning off the warming option in rice cookers. Males use significant amounts of electricity by keeping the rice cooker on for 24 hours continuously, and leaving desk lamps and lighting on continuously in the living room and bedrooms. The result illustrates that the patterns of electricity use are different according to the time period. The patterns of electricity use reflect relatively different lifestyles including habitual behaviors, electronic appliances used, the times that they are used, and gender.

\section{Electricity Consumption Based on Each Electricity Rate}

This chapter presents how energy consumption is changed by the elasticity of demand in electricity prices when TOU is applied to the pattern of six subjects' electricity use. According to the Korea Energy Economics Institute, the price elasticity of the demand for electricity by residence in Korea is 0.025 [22]. Thus, if the flat rate currently applied to each residence is changed to the TOU rate, the electricity consumption in the same time period will decrease or increase by responding to the changes in the price. For the six subjects, each variation applied to the electricity rate is as shown in Table 2.

Table 2.Total Daily Electricity Consumption Based on Each Electricity Rate

\begin{tabular}{cccc}
\hline \multirow{2}{*}{ Age-Sex Group } & \multicolumn{3}{c}{ Electricity Consumption [Wh] } \\
\cline { 2 - 4 } & Flat & TOU & Variation \\
\hline 66-male & 9278.28 & 9264.48 & -13.80 \\
65-female & 9328.52 & 9277.42 & -51.10 \\
34-male & 8987.04 & 8984.51 & -2.53 \\
36-female & 5452.89 & 5452.45 & -0.44 \\
21-female & 6461.29 & 6458.18 & -3.11 \\
20-male & 7401.19 & 7388.07 & -13.12 \\
\hline
\end{tabular}

The 65-year-old female subject displays the highest variation in value of -51.10 , while the 36-year-old female subject displays the lowest variation in value of .44. This change is shown with a dotted line in Figures 9 and 10 .

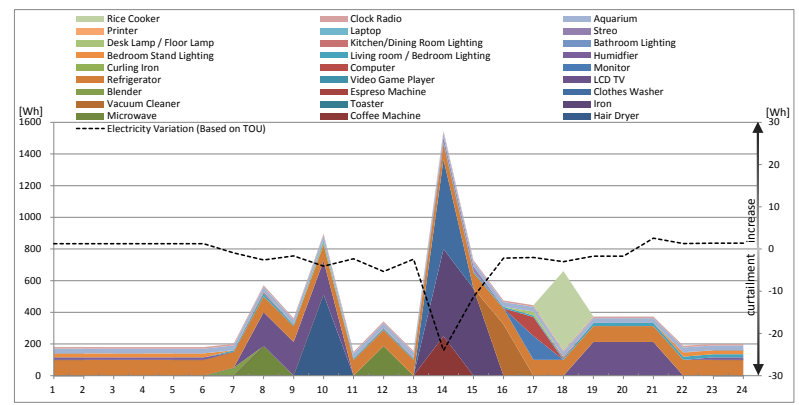

Figure 9. Female (65) Electricity Consumption Pattern

The reason the 65-year-old female has the highest value is that the time zone between $11: 00$ and 16:00 is the most expensive time zone for electricity. Therefore, if the use of electric appliances in this time zone shifts to the time zone between 21:00 and 07:00, to which the cheaper price is applied, the amount of energy consumption will be decreased.

On the other hand, the 36-year-old female displays the lowest electricity consumption among subjects because her electricity consumption does not primarily take place during the most expensive time zone. In this case, if the flat rate is changed to the TOU rate, the curtailment of electricity consumption is less than that for the 65-year-old female case. 


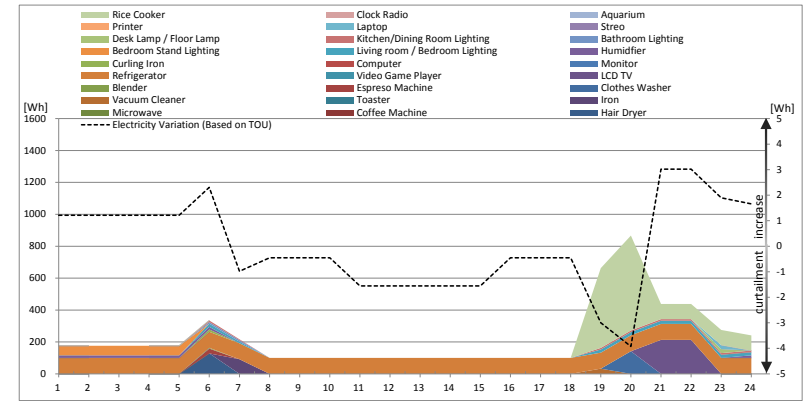

Figure 10. Female (36) Electricity Consumption Pattern

\section{Conclusion and Future Directions}

Although significant improvements in energy efficiency have been achieved in home appliances and lighting, the electricity consumption in households has continued to increase. The reasons for this could be associated with an increased degree of comfort and level of amenities [20].To understand energy consumption in single-households, the patterns of energy use of electronic appliances and entertainment loads were investigated with six representative subjects emphasizing different lifestyles.

Based on the patterns of the energy use, we expect that customized smart homes could be implemented to reduce energy consumption in each single-household. Rather than developing smart homes from a technologyoriented approach, residents' lifestyles, energy-related behaviors and habits should be considered as essential for the effective management of energy consumption in households. To reduce electricity consumption in single-households, the patterns of electricity use of the electronic appliances and lighting should be understood. Based on this understanding, a smart system that monitors the residents' patterns of electricity use could be provided to stimulate them to be conscious of potential energy savings. Through the monitoring, the residents become aware of unnecessary energy consumption in daily life, leading to the avoidance of such thoughtless behavior. For example, compared to females, males consume a great deal of electricity carelessly, for example, leaving the warm option on in a rice cooker and not turning off standard lamps; thus, there is not much difference in the total amount of electricity used even though males use less electronic appliances. Further, control systems customized to the patterns of the electricity use could be developed enabling smart time-scheduling for electricity consumption in single-households. In this study, a timescheduling system driven by TOU is proposed for the electricity consumption of the six subjects. The system sets different prices for electricity for each time zone; thus, the amount of energy consumption by electric appliances, which are used regardless of cheaper priced time zones, will be decreased and managed more effectively. For example, with the exception of the two elderly persons, the remaining four subjects consume electricity intensively in the morning and evening. If we employ a smart clothes washer or a robot vacuum cleaner that can be operated at a customized time, the electricity use can be distributed over the time period when less electronic appliances are being operated.

Although the sizes of the dwellings are not large, and therefore the number of lighting appliances is not high, electricity consumption for lighting is high because most subjects turn on the lights and leave them on continuously in the kitchen, living room and bedrooms in the evening. It seems that several activities occur simultaneously in those spaces, thus residents carelessly leave some of the lighting on. Further, females keep lighting on in the daytime because of their long-sightedness. Appropriate illumination appears to be different in the daytime and evening. Smart lighting systems could reduce unnecessary electricity consumption by controlling lighting according to the awareness of occupancy or the desirable illumination. Manual control systems could be better for some situations, thus more desirable options should be selected by considering the patterns of electricity use by single-households. This research is a preliminary study for proposing appropriate solutions to the effective management of energy use for single-households. By maximizing smart spaces in single-households, sustainable and healthy housing would be realized in single-households in terms of energy saving. Further, this research would be a basis for enhancing the quality of housing environments for single-households.

\section{Acknowledgements}

This work was supported by the National Research Foundation of Korea (NRF) grant funded by the Korea government (MSIP). (No. 2008-0061908)

\section{References}

[1] Institute, T.S., The Factors for the Changes in Electricity Consumption in Househlods in Korea, The Seoul Insititute: Seoul. 2013.

[2] Cho, M.E., A Study of Housing Design Guidelins for the Single Households. Journal of Korean Home Management Association, 20(6):219-227.2000.

[3] Ryu, J.-R.et al. A Study on the Application of Smart Technoloy in Single Household Space. In Proceedings of The Architectural Institure of Korea. 2005.

[4] E.Lundstrom, Occupant Influence on Energy Consumption in Single Family Dwellings, Swedish councile for Building Research. 1986.

[5] T.D.Pettersen, Variation of Energy 
Consumption in Dwellings Due to Climate, Building and Inhabitants. Energy and Buidings, 21:209-218.1994.

[6] Al-Mumin, A.et al., Occupants' Behavior and Activity Patterns Influencying the Energy in the Kuaiti Resdiences. Energy and Buidings, 35:549-559.2003.

[7] Kim, Y.-L.et al., A Study on the Electricity Consumption Propensity by Household Members in Apartment Houses Journal of The Korean Housing Association, 22(6):4350.2011.

[8] Sung-Heui, C. and Jung S.-J., A Study on the Energy-Lifestyle of Apartment Residents. Journal of the Korean Institute of Ecological Architecture and Environment, 11(3):1930.2011.

[9] Sanquist, T.F.et al., Lifestyle Factors in U.S. Residential Electricity Consumption. Energy Policy, 42:354-364.2012.

[10] G.Wood and M.Newborough, Dynamic Energy-Consumption Indicators for Domestic Appliances: Environment, Behavior and Design. Energy and Buildings, 35:821841.2003.

[11] Lee, E.-N. and Cho S.-I., An Analysis of the Sustainable Design for the Energy Saving Housing Prototype in Korea. Journal of Korean socienty Living Environment, 20(3):325-338.2013.

[12] Choi, T.-S.et al. Analysis of Energy Savings Using in-Home Display (Ihd) In Proceedings of The Korean Institute of Electrical Engineers. 2009.

[13] Choi, D.-S.et al. A Study of Remote Control and Management System for Energy Saving Hid Lamps In Proceedings of The Korean Society of Marine Engineering. 2010.

[14] Dounis, A.I.et al., Intelligent Control System for Reconsiliation of the Energy Savings with Comfort in Buildings Using Soft Computing Techniques. Energy and Buildings 43:6674.2011.

[15] Kim, T.et al., Optimization of Home Loads Scheduling in Demand Response Journal of the Korean Institute of Communications and Information Sciences, 35(9):1407-1415.2010.

[16] Won, A.-n.et al., An Anlaysis of ElectricPower Savinf Effect According to Energy Saving Behavior in Residential Sector. Architectural Institute of Korea, 29(8):231239.2013.

[17] Hu, K., The Analysis of Determining Factors Influencing for Energy-Saving Attitudes and Behaviors Related Electric Energy
Consumption Korean Family Resource Management Association, 14(3):53-68.2010.

[18] Westergren, K.-E.et al., Monitoring Energy Consumption in Single-Famiy Houses. Energy and Buildings, 29:247-257.1995.

[19] Lee, E.-J.et al. Study on the Effect of Reducing Consumption of Domestic Electric Power by Managing Model Energy Mileage System in Busan. In Proceedings of SAERK2009. 2009.

[20] Almeida, A.d.et al., Characterization of the Household Electricity Consumption in the Eu, Potential Energy Savings and Sepcific Policy Recommendations. Energy and Buidings, 42:1884-1894.2011. 